\title{
Management of Menstrual Hygiene among School- Going Adolescent Girls in an Informal Settlement in Nairobi, Kenya, Amidst COVID-19 Pandemic
}

\author{
Joy N. Mokaya ${ }^{1}$, Mary Muiruri ${ }^{1}$, Francisca Ongecha $^{2}$ \\ ${ }^{1}$ Department of Community Health and Epidemiology, School of Public Health, Kenyatta University. \\ ${ }^{2}$ Department of Psychiatry and Mental Health, School of Medicine, Kenyatta University. \\ Corresponding Author: Joy N. Mokaya
}

DOI: https://doi.org/10.52403/ijhsr.20220235

\begin{abstract}
Puberty is a critical stage for key social-emotional changes and intellectual developments in the transition to adulthood. The lack of knowledge about menstruation and the inefficiency of resources to properly manage body changes consequently leads to anxiety and fear during the transition for some adolescents, especially in low- and middle-income countries. Every girl needs to have access to learning, wellbeing, and future forecasts about menstruation and guidance towards effective menstrual hygiene management. Several adolescent girls and women in informal settlements have a partial understanding of their bodies' growth and development. Therefore, this study aims to assess the management of menstrual hygiene among school-going adolescent girls in Kibera, Nairobi City County, Kenya. A descriptive cross-sectional study design was used with cluster sampling in the selection of schools and a purposive sampling to recruit respondents for the study. A self-designed structured questionnaire, interview study guide, and an observation checklist were used. The data findings were analyzed using SPSS version 23 . The study was conducted among 442 adolescent girls from 22 primary schools who resided in the area when the study was carried out. $80 \%$ of school-age adolescent girls in Kibera have general knowledge of menstruation being a normal process for the transition of every girl into womanhood. On the contrary, $20 \%$ consider it culturally unclean, as menstruation is still considered a taboo. Almost $98.8 \%$ of adolescents use some form of menstrual absorbent material, with $86 \%$ using a sanitary pad during menstruation. Most schools had separate toilets for boys and girls. Due to COVID-19 protocols, $96 \%$ of schools had a handwashing facility equipped with soap and water. However, $80 \%$ of the schools did not have water for menstrual hygiene. The findings of the study in Kibera recommend that schools introduce a specific reproductive health study guide to be incorporated for teaching menstruation in schools.
\end{abstract}

Keywords: Menstruation, school-going adolescents, management of menstrual hygiene

\section{INTRODUCTION}

Adolescence in girls has been documented as a distinct era in their growth and development with the onset of menarche. This is a significant milestone for the transition of every daughter to adulthood (1). The well-being is as vital as the social status of adolescent girls, as they are a susceptible group (2). Universally, Menstrual Hygiene Management (MHM) is a key health concern that affects women of reproductive age (3).

Optimal management of menstrual hygiene involves access to essential resources, amenities, and training in MHM (World Health Organization and the Joint Monitoring Program of the United Nations Children's Fund, 2012). Globally, nearly half of the population, from personal experience, discerns the importance of 
optimal menstrual hygiene in being able to function supremely even during their menses (4). Despite growing local and global attention to Menstrual Health Management and the impact on girls, significant knowledge gaps still persist (1)(5).

The management of menstrual problems for several women in low- and middle-income countries is an inescapable hurdle. In Karachi slums in Pakistan, adolescent girls were the hardest hit in managing menstrual cleanliness as a result of the privation of a framework to discard recycled cloths while attending classes in addition to the discretion deprivation to dry washed ones in their households (6). Furthermore, research documentary stories from low- and middle-income school girls in Ethiopia, Tanzania, Kenya, Nepal, Uganda, and India expose a range of difficulties in managing menses in school environments (1).

A recent demographic survey revealed that $20 \%$ of the Kenyan population are adolescents of which $52 \%$ live in slums in Nairobi. Several adolescent girls and women in Kibera and other informal settlements have partial understanding of the growth and development of their bodies (7). Whereas a substantive number of youths may be armed with the information, indulgence, and expertise to cater for their essentials and receive upkeep, when necessary, numerous others are neither prepared nor sustained in their adulthood transition (8). It is vital to address the fundamental menstrual concerns that prevent adolescents from achieving their full potential while learning and living their normal daily lives. Comprehension and contemplation of the ways pubertal girls consider womanhood (experiences anticipated on menstruation days during their learning) in their domain is important (9).

Pubertal menstrual sanitization and personal care is a precarious concern that determines the state of well-being of the adolescent and the ultimate practices that are indoctrinated in their mature years (10). Furthermore, without basic necessities, there is a hindrance to optimal menstrual hygiene management of young girls. Adolescents residing in this region are not exempted. Among different places and in Kenya, numerous adolescent girls experience exposures and extensive dangers that deter a fruitful, vigorous, and safe transition into early adulthood (11). In Nairobi slum residences, including Kibera, young women undergo a number of trials in their transition to adulthood. They are exposed to living in an unreceptive shanty setting, written off by viciousness, compromised living, destitute learning infrastructure, redundancy, enormous family groups, misconduct, and drug and alcohol abuse (12). Therefore, the objectives for this study were to 1) identify menstrual hygiene practices among schoolgoing adolescent girls in Kibera, 2) assess the level of knowledge and perception on menstrual hygiene among school-going adolescent girls in Kibera, and 3) assess the provisions for menstrual hygiene management in school-based facilities.

\section{MATERIALS AND METHODS Research Design}

A descriptive cross-sectional design was adopted for this study. The results from cross-sectional surveys not only provide a sign of the scale of the problem in a particular population at a particular point in time, but also give a basis for designing appropriate public health measures.

\section{Location of the study}

Kibera is a constituency of Nairobi County, situated around $5 \mathrm{~km}$ from Nairobi (CBD). It is one of the largest informal settlements in Kenya. The area is characterized by lack of access to water and sanitation facilities, high unemployment, and high rates of HIV AIDS (13)(14)(15).

\section{Study population}

The research study was conducted among school-aged girls who were fully registered for the term when the research 
Joy N. Mokaya et.al. Management of menstrual hygiene among school-going adolescent girls in an informal settlement in Nairobi, Kenya, amidst COVID-19 pandemic.

was carried out. This was only inclusive of students enrolled for grade 4 and class 8 regardless of their place of residence (within or outside of the Kibera slum).

\section{Sampling Techniques and Sample Size Sample size determination}

The sample size for this research study is derived from Fisher's formula as shown below (16):

$n=\frac{z^{2} q p}{e^{2}}$

Where;

$\mathrm{z}=$ standard normal deviation for $\alpha$ at $95 \%$ confidence, $\mathrm{Z} 1-\alpha / 2=1.96$

$\mathrm{p}=$ estimated proportion of menstruating school-going adolescent girls (0.5)

$\mathrm{q}=1-\mathrm{p}(0.5)$

$\mathrm{d}=$ precision level (margin error) at $5 \%$ (0.05)

n0 $=$ sample size $=384.16385$

The maximum assumption variability in the proportion of girls menstruating was, $\mathrm{p}=0.5$, that is, the maximum variability. This included a $10 \%$ nonresponse rate (girls who returned the consent forms and due to the Covid-19 restriction only grade 4 and class 8 were in school during data collection), the sample size used for this study was 442 .

\section{Sampling technique}

This research study used a cluster sampling technique, in which at least seven schools from each ward in the constituency comprised the study cluster schools. Purposive sampling was used to recruit and target the required number of participants in each school in the cluster. The calculated sample size of 442 was divided proportionately among the three wards (Sarang'ombe, Makina and Laini Saba wards) of the Kibera constituency. For example, in the event Ward A accounts for $30 \%$ of the total population of school going adolescent girls from the three wards, then $30 \%$ of the sample (approximately 127 individuals) will be drawn from that ward. This was informed by the logistical limitations of the traversing around the study area. Due to the Covid-19 guidelines and restrictions, during the data collection only the grade 4 and class 8 students were present at the schools who fell within the 3 sets of age groups (11-13years, 14-16 years and 16-18 years), to capture data of all the age groups of the girls within the adolescent bracket as shown in table 1 .

Table 1: Number of respondents per school

\begin{tabular}{|l|l|l|l|}
\hline School Code & Name of Primary School & No. of Girls Interviewed & No. of KII Forms Filled \\
\hline$\# 001$ & Calvary Educational Center & 8 & 3 \\
\hline$\# 002$ & Adventure Pride Primary School & 8 & 2 \\
\hline$\# 003$ & Kicoshep Laini Saba Primary School & 15 & 2 \\
\hline$\# 004$ & Fafu Educational Center & 12 & 2 \\
\hline$\# 005$ & Chemi Chemi Ya Tumaini Primary School & 9 & 2 \\
\hline$\# 006$ & Cherry Educational Center & 12 & 2 \\
\hline$\# 007$ & Good News Primary School & 6 & 2 \\
\hline$\# 008$ & K.A.G (Olympic) Primary School & 21 & 2 \\
\hline$\# 009$ & St. Martins Primary School & 7 & 2 \\
\hline$\# 010$ & Spurgeons Primary School & 16 & 2 \\
\hline$\# 011$ & Olympic Primary School & 113 & 2 \\
\hline$\# 012$ & Jeremic Academy & 14 & 2 \\
\hline$\# 013$ & Kibera Primary School & 79 & 3 \\
\hline$\# 014$ & Green Pastures Primary School & 20 & 3 \\
\hline$\# 015$ & Toi Primary School & 15 & 3 \\
\hline$\# 016$ & Utu Primary School & 24 & 3 \\
\hline$\# 017$ & Three Bells Primary School & 9 & 2 \\
\hline$\# 018$ & Dessert Stream Primary School & 11 & 3 \\
\hline$\# 019$ & Glory Primary School & 8 & 2 \\
\hline$\# 020$ & Garden Of Hope Educational Center & 11 & 2 \\
\hline$\# 021$ & Ushirika Children's Center & 12 & 3 \\
\hline$\# 022$ & Kibera Free Methodist Primary School & 13 & 3 \\
\hline Total Number & & $\mathbf{4 4 2}$ & $\mathbf{5 2}$ \\
\hline
\end{tabular}


After receiving approval from the relevant authorities, class registers of those in attendance were used to select research participants by systematic sampling. Hereby, odd numbers were used from the register as sampling interval as a fixed periodic interval for participation selection. For example, via the register, the 1st, 3rd, 5th, 7th, 9th, 11th, 13th... 21st... girl from the attendance list were systematically chosen as research participants.

The respondents included a list of the number of adolescent girls who had already undergone menarche and who submitted the approved parental consent forms from their guardians. Due to the restrictions of the COVID-19 pandemic, we focused on the grade 4 and class 8 students who were present in the schools during the interviews. The key informants consisted of school administrators and subject teachers who had reported at the schools mainly to teach grade 4 and class 8 learners.

\section{Validity and reliability}

The validity and reliability of the questionnaire was determined as follows. Validity of face and content was determined based on the points of view of adolescents and teachers.

\section{Reliability}

The reliability of the test-retest was examined using a pre-test with 35 qualified and available female adolescent girls. These girls were not part of the study. The questionnaire was reviewed and analyzed for repeatability and internal consistency aspects. The Cronbach alpha coefficient was used to assess internal consistency. Repeatability was estimated using the interclass correlation coefficient (ICC), where ICC reliability ranges of less than 0.4 is poor, $0.4-0.7$ is fair to good, $0.6-0.8$ is good and $0.8-1$ is excellent.

\section{Data collection techniques}

In the study, both primary and secondary data were collected. Primary data on knowledge and practices on menstrual hygiene management was collected using a pre-designed structured questionnaire among 442 girls in the selected wards. Research assistants were assigned to the different wards where questionnaires were distributed to the selected sample population. Key informant interviews with teachers were conducted to understand accessibility of sanitary towels and their perspectives on the specific needs and common problems of menstrual hygiene management for adolescents in schools, as well as the mechanisms of resolution. Secondary data on the population were collected from county health records. The collected data was coded, entered into the computer using Microsoft Excel, cleaned, checked for discrepancies, and rectified.

\section{Logical and Ethical Considerations}

The Kenyatta University Board of Postgraduate Studies approved this research study. Kenyatta University Ethics Review Committee provided ethical clearance to conduct this research, and the National Commission for Science, Technology \& Innovation (NACOSTI) gave permission to conduct this research. To access the different schools in Kibera slum, authorization was granted by Nairobi City County, Ministry of Education, and Directorate of University Education. Parents' consent was sought from the guardians of the leaners and informed consent / consent was obtained from all participants and teachers who participated in the study. Confidentiality and volunteerism to participate was observed. Only the participants present during the study participated.

\section{Data Analysis}

IBM SPSS version 23 statistical software was used to analyze the data. The first stage in the data analysis of all types of variables consisted of scanning the data set to establish basic descriptive statistics that allowed a first approximation to the pattern of behavior of each variable included in the data set. This assisted to assess the relative 
effectiveness and success of the data cleaning and consistency controls already executed. For discreet variables, frequency tables with single or multiple crossclassification criteria elucidated the knowledge and practices of the study population on menstrual hygiene management and conditions of menstrual hygiene management facilities. For continuous variables, measures of central tendency (mean) and measures of dispersion (standard deviation) are provided. Sampling and measurement errors are provided. Qualitative data in key informant interviews were analyzed by content analysis. The results from descriptive analyses are presented in frequency tables and figures.

\section{RESULTS}

A total of 442 adolescent female students in Kibera participated in the research study. Female students were constituted in the ratio of 5 to 216 for grade 4 and 8 . The low number of grade four female students was attributed to the low return rate of consent forms and probably because most of the women did not experience menstruation. The mean age of the students was 14.14 years, with a standard deviation of 1.041, and the ages of the girls ranged from 11-18 years, respectively. This shows that most of the women in adolescence who menstruate were 14 years and older. $61 \%$ of in-school adolescent female students lived with both parents, while $23.9 \%$ of them lived with their mother only. The remaining $15.1 \%$ had been living with their father, sibling, grandfather, aunt or uncle during the time of the survey. Mostly, $48.6 \%$ of the guardians were casual workers, while a little less than a third $(32.9 \%)$ of them were entrepreneurs. This implies that most of the adolescent girl students lived in families with a limited budget.

\section{Level of knowledge on menstrual hygiene among school-going adolescent girls in Kibera Girls' Responses}

The majority of $87.3 \%$ (386) of the girls responded that they had received general information about menstruation at school, while $11.8 \%$ (52) stated that they learned from other sources (a guardian, close friend, or sibling) and $0.9 \%$ (4) had no information about menstruation.

Only $39.4 \%$ (174) of the girls reported learning about menstruation during extra-curricular school programs, mainly through health clubs in partnership with various NGO sponsorships that varied from school to school. However, $63.5 \%$ (33) of the key informants reported having personally taught menstruation to the girls or were aware that the girls were taught on menstruation at school, while $36.5 \%$ (19) responded that the girls were taught menstruation at home or through their sponsors, that is, Non-Governmental Organizations (NGOs) or Community Based Organizations (CBOs). On the contrary, $78.8 \%$ (41) of the key informants admitted that girls were taught menstruation through the basic knowledge and experience of health teachers or sponsors, while $21.2 \%$ (11) stated that they used a specific reproductive health study guide to teach girls menstruation.

The highest number of girls $(36.5 \%$, 160) reported to have first received information on menstruation in class 7 of ages ranging from 11 to 13 years while $29 \%$ (127), $25.6 \%$ (112), $6.2 \%$ (27) 2, 1.1\% (9), $0.5 \% \quad(2), \quad 0.2 \% \quad(1)$ having received knowledge on menstruation in classes $6,8,5,4,3$ and 2, respectively, all between ages 8-14 years. However, most reported being personally aware of menstruation only after experiencing menarche. This slightly differed with the responses from the Key informants who stated that the majority of the girls initially receive menstrual knowledge from class 3 to class 6 some as early as 6 years to above 11 years, respectively, this varied from one school to another.

Most of the girls had accurate knowledge about menstruation, as shown by $85 \%$ (376) reporting that menstruation is received once every month, $10 \%$ (44) did not know the frequency of menstruation 
since they had only begun menstruating, with $2.5 \%$ (11) and $2.5 \%(11)$ stating that menstruation occurs once every two weeks and once every two months correspondingly. Mainstream, $91.8 \%$ (406) reported the accurate interval of a female's menses as at least 3-7 days while $3.2 \%$ (14) and $5.0 \%$ (22) stated that menstruation would occur for less than 3 days, and the latter indicated that they were unaware of the number of days of menstruation.

\section{Management of menstruation hygiene taught at school}

A high percentage $(59.6 \%, 31)$ reported having taught adolescents menstruation through organized health and girl club meetings in partnership with sponsorship from NGOs and CBO. It was observed that $38.5 \%$ (20) of the key informants reported that some of their teachers had been certified to teach girls menstrual hygiene management while $61.5 \%$ (32) do not have any form of training in menstrual hygiene management or reproductive health. The results also indicate that there is a correlation between the percentage of menstrual knowledge of adolescent girls and the percentage of trained teachers as statistically significant as the level of significance is at 0.052 . Furthermore, there is a positive correlation between the two variables, which implies that increased training of teachers leads to an increase in the level of menstrual knowledge of adolescent girls. If more teachers are trained on reproductive health issues (including menstruation and menstrual hygiene management) through sponsorship by various stakeholders, girls will be able to make informed decisions on their choice of menstrual product, menstrual hygiene practice, and achieve optimum menstrual hygiene management. This further reveals that a supportive MHM environment inclusive of premenstrual education and reproductive health, among other essentials, provides an equal opportunity for all girls to transition into womanhood safely and with dignity.

\section{Menstrual hygiene practices among school-going adolescent girls in Kibera}

The majority $(86 \% \quad(380)$ of adolescent girls use sanitary pads, 5.4\% (24) use both a sanitary pad and a reusable cloth, $4.8 \%$ (21) use menstrual cup, $3.6 \%$ ( 16) use cotton wool or a reusable cloth, and $0.2 \%$ (01) use no sanitary material during menstruation as shown in Table 2. Further findings do not show a significant correlation between guardian occupation and the sanitary material used by menstruating girls. The correlation value is greater than 0.05 , indicating that the two variables are not associated. The extensive use of sanitary towels/pads may be accredited to the present support of menstrual materials from the government, NGOs, CBOs, religious groups among others in the various schools. Most of the $78.8 \%$ (41) reported washing their reused sanitary material with soap and water, while $15.4 \%$ (8) and $5.8 \%$ (3) have used only water and antiseptic for the latter.

Table 2: Menstrual Hygiene Practices among School-going Adolescent Girls in Kibera

\begin{tabular}{|l|l|l|}
\hline Categories & Freq. & $\%$ \\
\hline Sanitary Material Used & 380 & $86.0 \%$ \\
\hline Disposable pad & 8 & $1.8 \%$ \\
\hline Reusable cloth & 8 & $1.8 \%$ \\
\hline Cotton wool & 24 & $5.4 \%$ \\
\hline Disposable pad and reusable cloth & 21 & $4.8 \%$ \\
\hline Menstrual cups & 1 & $0.2 \%$ \\
\hline None & 206 & $46.6 \%$ \\
\hline Material used to clean genital area when menstruating \\
\hline Water & 108 & $24.4 \%$ \\
\hline Soap and Water & 6 & $1.4 \%$ \\
\hline Antiseptic & 79 & $17.9 \%$ \\
\hline Cloth, water and soap & 16 & $3.6 \%$ \\
\hline Salt and water & 27 & $6.1 \%$ \\
\hline Cloth/tissue/towel/ Handkerchief & 8 \\
\hline Material used to wash re-used sanitary material \\
\hline Water & 81 & $15.4 \%$ \\
\hline Soap and Water & 3 \\
\hline Antiseptic & $78.8 \%$ \\
\hline
\end{tabular}

However,74.9\% (331) of the girls reported changing their menstrual material 3-4 times a day, $11.5 \%$ (51) changing 1-2 times a day, $7.5 \%$ (33) changing 5-6 times a day, $1.6 \%$ (7) changing 7-8 times a day, $4.5 \%$ (20) unaware of how many times in a day they would change their menstrual materials.

A mere $12.2 \%$ (52) stated to be reusing their sanitary material, while the 
Joy N. Mokaya et.al. Management of menstrual hygiene among school-going adolescent girls in an informal settlement in Nairobi, Kenya, amidst COVID-19 pandemic.

majority $87.8 \%$ (374) do not reuse their sanitary material.

\section{Perception of menstrual hygiene management among school-going adolescent}

The majority (94\% (414) of the adolescent girls in the study agreed that menstruation is a natural process and not a shameful process, a curse, or a disease. However, $22.1 \%$ (96) of the respondents stated that menstruation was considered culturally unclean as shown in Figure 1.

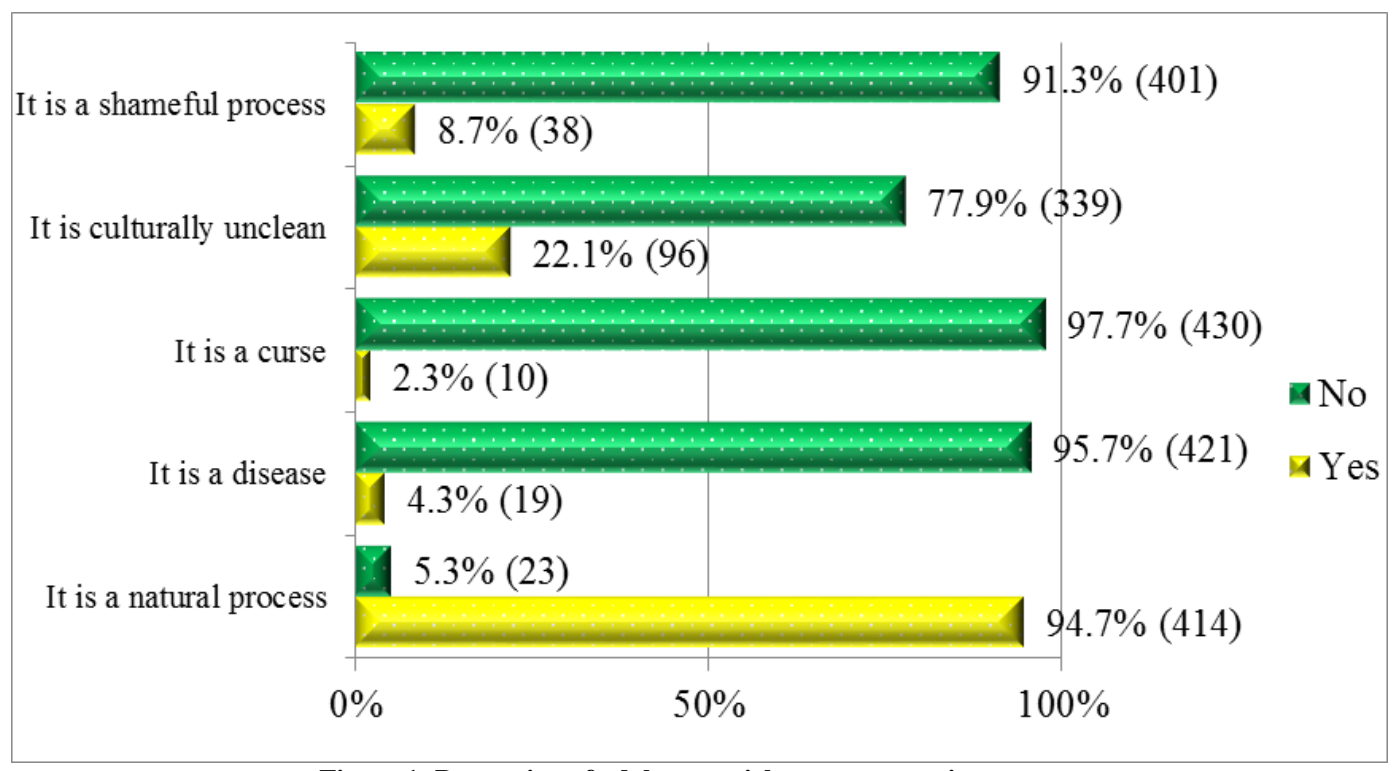

Figure 1: Perception of adolescent girls on menstruation process

\section{Perception of menstrual hygiene management}

Further findings show that there is no correlation between the perception of adolescent girl about MHM and her menstrual knowledge, as the level of significance is 0.888 , which is greater than 0.05 , indicating that the two variables are not statistically significant. Therefore, the majority of the girls in schools have received relevant knowledge on menstruation resulting in the perception that menstruation is a natural transition to womanhood, this can be attributed to the heavy presence of NGOs within Kibera that provide knowledge and support to schools $(69.2 \%)$, as reported by 32 of 52 key informants interviewed. With increased communication, information, training of teachers in schools and support from sponsors and stakeholders, adolescents would be better equipped and would greatly reduce stigma and old women tales, and hence menstruation would be normalized.
Provisions for menstrual hygiene management in school-based facilities Internal or external support in MHM to the school

A substantial $75 \%$ (39) of the key informants reported receiving external support interventions in the management of menstrual hygiene in the form of menstrual products distributed to girls, while the remaining $25 \%$ (13) only fully relied on guardians or school to provide menstrual materials. $86.5 \%$ (45) of the informants stated that they received the intervention as a subsidiary of the government, NGOs, $\mathrm{CBO}$, professional and religious groups for menstrual products, the remaining $13.5 \%$ (7) resorting to self-sponsorship for the menstrual products provided for girls. Only $17.3 \%$ (9) of the informants reported being beneficiaries of the Kenyan government's Sanitary Towel Program.

There was a significant low supply of menstrual products for schools whereby the distribution cycle varies from one school to another depending on the level and 
consistency of intervention with respect to the number of menstruating girls per school. Half of the informants $(50 \%, 26)$ reported to distributing the menstrual products to the girls through a specific female teacher while the rest distributed the menstrual products through the health club meetings, particular arrangement with the sponsors, the female nurse or head teacher, respectively.

\section{The cycle of distribution of sanitary towels to the various schools of the sponsors}

$73.1 \%$ (38) of the key informants reported a low distribution cycle of menstrual materials to girls, citing that menstrual products were not sufficient for girls while at school. 96.2\% (50) of the informants reported having provisions for the sanitary materials for the girls in cases of emergency or accidental leakage, while $3.8 \%$ (2) reported sending the girls to manage their menses from home. The key informants provided a variety of recommendations, with the most common having requested increased sanitary materials and panties for the girls from the Kenyan government and other sponsors and stakeholders. There was also an additional request to provide premenstrual awareness and education to boys, girls, and guardians, among other recommendations.

\section{Observations from the School Facility}

A substantial number of schools $(90.9 \%, 20)$ had sanitary facilities within the school compound. The type of sanitary facility varied from school to school, with facilities ranging from mobile toilets $(5 \%$, $1)$, VIP latrines $(75 \%, 15)$ and traditional pit latrines $(20 \%, 4)$. The location of the toilets for girls for most schools was mainly within the school compound $(80 \%, 18)$ as shown in Table 3.

Table 3: Status of the sanitary facilities in the school

\begin{tabular}{|c|c|c|c|c|c|}
\hline Category of sanitary unit & Functional & $\begin{array}{l}\text { Partially } \\
\text { functional }\end{array}$ & $\begin{array}{l}\text { Not } \\
\text { functional }\end{array}$ & $\begin{array}{l}\begin{array}{l}\text { Locked (unable to } \\
\text { access) }\end{array} \\
\end{array}$ & Total \\
\hline Exclusively for girls & $32(35.6 \%)$ & $50(55.6 \%)$ & $1(1.1 \%)$ & $7(7.8 \%)$ & 90 \\
\hline For boys or girls/communal & $27(29.7 \%)$ & $52(57.1 \%)$ & $3(3.3 \%)$ & $9(9.9 \%)$ & 91 \\
\hline Exclusively for female teachers or female staff & $34(87.2 \%)$ & $5(12.8 \%)$ & - & - & 39 \\
\hline For female or male teachers and staff & $26(65 \%)$ & $10(25 \%)$ & $1(2.5 \%)$ & $3(7.5 \%)$ & 40 \\
\hline $\begin{array}{l}\text { For use by anyone in the school (students/teachers, } \\
\text { male/female) }\end{array}$ & $2(100 \%)$ & - & - & - & 2 \\
\hline
\end{tabular}

The number of functional sanitary units exclusively for girls also varied from school to school with three schools having 8 to 19 sanitary units, with a higher number of schools $(85 \%, 17)$ having $2-4$ sanitary units per school. Slightly more than half the number of sanitary units within the schools (55.6\%, 50 sanitary units) were partially functional, as most were not lockable from the inside of the toilet, with $35.6 \%$ (32) being fully functional while the other remaining sanitary units were locked $(7.8 \%$, 7) and inaccessible for use $(1.1 \%, 1)$

The higher majority of schools (85\%, 17 schools) had separate sanitation facilities for boys or girls, while (15\%) 3 schools did not separate units for either gender. Further results indicated that the correlation between the lack of separation of the toilets for girls and boys and the number of times an adolescent girl changes her sanitary material (MHM practice) is not statistically significant. This is because the level of significance is at $p=0.224$, which is above 0.05, and therefore there is no association between the two variables. This suggests that most schools have toilet separate for both gender enabling girls to comfortably change their sanitary materials in privacy.

\section{Availability of MHM for girls in schools}

Due to COVID-19 protocols, most schools (96\%, 21 schools) had handwashing facilities with water and soap. However, at the time of the visit, $80 \%$ (16) of the schools did not have water for menstrual hygiene. Consequently, this would result in difficulty for girls who use reusable cloths to wash their sanitary materials or even wash and 
Joy N. Mokaya et.al. Management of menstrual hygiene among school-going adolescent girls in an informal settlement in Nairobi, Kenya, amidst COVID-19 pandemic.

change clothes in cases of accidents or for general menstrual hygiene practices. In terms of menstrual product disposal, only (80\%, 16 schools) had sanitary bins in the toilets, with only 6 out of the 22 schools having a pit to burn the used and one school having an incinerator. Most other schools reported having menstrual pads thrown in the latrines or adolescents going home with the menstrual products used.

\section{Availability of MHM in the school}

Further results show that there is strong statistical significance between the presence of an incinerator/ pit and the presence of disposal bins in the sanitary units for disposal of used sanitary products. The level of significance is 0.010 . In this study, most schools $(65 \%)$ had disposable bins where adolescent girls and teachers would dispose of their used sanitary products, while the remaining (35\%) would dispose of them through the pit latrines or "take them home". The disposable bins would be emptied to a well-dug pit or incinerator within the school compound.

\section{Hypothesis}

Ho: Perceptions are not correlated with menstrual hygiene management among school-going adolescent girls in Kibera.

Table 4: Correlation between Perceptions and Management of Menstrual Hygiene among school-going adolescent girls in Kibera

\begin{tabular}{|l|l|l|}
\hline \multicolumn{2}{|l|}{ Variable } & $\begin{array}{l}\text { Menstrual } \\
\text { Management }\end{array}$ \\
\hline Perceptions & $\begin{array}{l}\text { Pearson } \\
\text { Correlation }\end{array}$ & 0.003 \\
\cline { 2 - 3 } & Sig. (2-tailed) & $\mathbf{0 . 9 5 6}$ \\
\hline
\end{tabular}

Based on the findings above, it can be stated that perceptions are not correlated with menstrual hygiene management among school-going adolescent girls in Kibera. This is because the p-value is greater than 0.05 indicating that there is no statistical significance between the two variables. Hence, the null hypothesis is accepted as is indicated.

Ho: The level of knowledge about menstrual hygiene is not related to menstrual hygiene practices amongst the school going adolescent girls in Kibera.

Table 5: Correlation between knowledge on menstrual hygiene and menstrual hygiene practices

\begin{tabular}{|l|l|l|}
\hline \multicolumn{2}{|l|}{ Variable } & $\begin{array}{l}\text { Menstrual Hygiene } \\
\text { Practices }\end{array}$ \\
\hline $\begin{array}{l}\text { Menstrual Hygiene } \\
\text { Knowledge }\end{array}$ & $\begin{array}{l}\text { Pearson } \\
\text { Correlation }\end{array}$ & $-0.137^{* *}$ \\
\cline { 2 - 3 } & Sig. (2-tailed) & $\mathbf{0 . 0 0 5}$ \\
\hline \multirow{2}{*}{$* *$ The correlation is significant at the 0.01 level (2-tailed). }
\end{tabular}

Based on the findings above, the level of knowledge on menstrual hygiene is related to menstrual hygiene practices among school-going adolescent girls in Kibera. This is because the p-value is 0.005 , an indication that there is a strong statistical significance between the two variables. Hence, the null hypothesis is rejected, and the alternative is accepted as indicated below.

Alternative: The level of knowledge about menstruation is related to menstrual hygiene practices among school-going adolescent girls in Kibera.

\section{DISCUSSION}

The majority of the girls $(87.3 \%$, 386) individually confessed to being mostly uninformed during pre-menarche, as most came to have a better understanding and became self-aware only when they had personally experienced menstruation. This result concurs with a previous study in India (17). Knowledge of the menstruation cycle is essential for every adolescent girl to have during pre-menarche for menstrual hygiene management.

According to Chet (18), accurate prior knowledge on matters related to menstruation is important for every adolescent girl to avoid distress, remorse, and shame. Findings by Amaya (19) suggested that variations in one's menstrual cycle during the years of female reproduction point to a variety of health illnesses such as malnutrition and cancer. Additionally, the number of days in a month and the total number of days of menstruation for females varies depending on their knowledge of menstruation and 
personal medical condition at the time of the research interviews.

During the interviews, most of the key informants addressed menstruation as a 'taboo' at school and in the community. This study coincides with a previous study by E. Korir (20), which reported menstruation as a taboo and that it influenced limited sharing of information on menstrual hygiene management. This results in challenges for adolescent girls in Kenya and other developing countries.

Most $(61.5 \%, 32)$ of the key informants stated that their teachers had not been trained on reproductive or menstrual matters. These research findings also indicate that there was a strong significant correlation $(\mathrm{p}=0.052)$ between the menstrual knowledge of adolescent girls and trained teachers.

\section{Menstrual hygiene practices}

Most girls $(86 \%, 380)$ reported using sanitary pads as their preferred choice of menstrual material. This is similar to a previous study in Malawi where a majority opted to use sanitary pads compared to menstrual cups, as they considered the menstrual cups too technical to use (21). This study also contradicts previous studies in India (22) and rural Nepal (23) with the least number of respondents having used sanitary pads.

However, most of the girls in this study reported having difficulty accessing the sanitary pads during school holidays. Consequently, the girls opted to use alternative menstrual materials, as sanitary materials were an expensive commodity to purchase by their guardians, as they would normally receive menstrual products at school. This study correlates with a previous study in Rwanda where most girls reported that the sanitary pads were unaffordable and, as a result, used homemade alternatives (24).

Some adolescent girls $(14 \%, 62)$ did mention challenges in having an underwear to change, this coincided with research conducted in Zambia (25). Adolescent girls seem to have a good menstrual hygiene practice because a higher majority who used some form of menstrual absorbent $(98.8 \%$, $441)$ and would change their menstrual material from 3 to 8 times a day $(84 \%, 371)$, including washing their reusable sanitary material, drying them against sunlight, and cleaning their genitalia with water $(93.9 \%$, 415), this helps prevent the manifestation of bacteria. This is supported by a similar previous study in Bangladesh (26)(26) and in Ghana (27).

Based on the findings above, the level of knowledge on menstrual hygiene is related to menstrual hygiene practices among school-going adolescent girls in Kibera. This is because the p-value is 0.005 , an indication that there is a strong statistical significance between the two variables.

In this study, there was no correlation between the type of sanitary material used and the occupation of the guardian. The level of significance is 0.068 . This can be attributed to the provision of hygiene materials by the school from the sponsors. This contradicts a similar study conducted in India, which suggests that occupation influences the choice of sanitary pad used. Whereas those from the lower income class opted for a piece of cloth as sanitary material used, those in the middle income class would have more concern of the cultural taboos while those of the lower income group would be more concerned about the economic implications of the purchase of the sanitary pads(28).

\section{Perception on menstruation}

The respondents $(87.3 \% \quad 386)$ requested general knowledge about menstruation as it is a normal physiological process that occurs in all girls and women of reproductive age. However, 23\% of adolescent girls reported that menstruation is 'culturally unclean'. This is similar to previous studies in Ghana (29), Ethiopia (30) and India where many young women who had received various views that menstruation was impure or dirty, and during menstruation one was prohibited 
from attending worship activities or perform 'puja' among other cultural practices (17).

Menstruation can be normalized with further training of teachers and this will increase awareness of pre-menarche knowledge and management of menstrual hygiene for adolescent girls. This is similar to a study reported in Zambia by Chinyama (25). This also corresponds to the Menstrual Hygiene Management Policy (2019-2030) in Kenya, which advocates that if women were well informed prior to menstruation about their physiques and access to accurate information, this would reduce stigmatization and also assist adolescents to make informed decisions on which menstrual product to use depending on their basic necessities and financial ability.

Based on the findings, it can be stated that perceptions are not correlated with the management of menstrual hygiene management among school-going adolescent girls in Kibera. This is because the p-value is greater than 0.05 (0.0956), indicating that there is no statistical significance between the two variables.

In this study, there was no significant correlation between perception of menstruation and practice of menstrual hygiene management. The level of significance is 0.888 . These results conflict with research carried out in Uganda by Boosey (31). That study showed that most girls viewed menstruation and MHM as a shameful and embarrassing experience that they were not free to share about when asked, providing little or no information about the practice of MHM.

\section{Provision for menstrual hygiene management in school facilities}

Most of the schools $(85 \%, 17)$ had separate toilets for girls, boys and teachers, respectively, with 2 of the 22 schools having sanitation facilities outside the school compound. This indicates that the girls were able to change their menstrual material or use the toilets as often as they needed in private. These results conflict with a research conducted in Northern Kenya by
Korir (20), which states that a third of the pastoralist school-going adolescent girls had poor MHM practice as a result predominantly determined by lack of latrine $\operatorname{privacy}(\mathrm{p}=0.025)$ and fear of teasing by boys $(\mathrm{p}=0.016)$ among others.

Some informants $(22.7 \%, 5)$ from schools reported reduced absenteeism of girls during their menstruation due to increased support from sponsors. Latrine privacy is paramount for menstrual hygiene management for the girls to, have during their visits to the sanitary facilities. A previous study in rural schools in Zambia illustrated that some girls opted not to change their toilets at school because the girl's toilet either did not have lockable doors or had no doors, therefore, girls could not change their toilet material as often as they would like, with some preferring to change their toilet material at home. This was also because they wanted to have less teasing from the boys as is the norm in previous studies in different other countries (25).

At least $65 \%$ of schools had sanitary bins in the toilets where most of the girls disposed of their used menstrual products. This concurs with a study in Dhaka, Bangladesh, which illustrated that used menstrual products were thrown into toilets, sanitary bins, and water bodies, among other areas (26). This study differs from a previous study in Zimbabwe that resulted in the majority of the respondents preferring to dispose of their used sanitary pads in discrete dumping sites far from home or school, as it was taboo that their used sanitary material should not be seen by others (32).

An adolescent girl needs to bathe or wash her soiled inner garments or uniform due to an 'accident' while at school. However, it was observed that out of the 22 schools in our study, three (3) had provision of water for menstrual hygiene while out of the three, only one (1) had a water basin present, while the rest of the schools (18) had no provision of water for menstrual hygiene. Almost $46.6 \%$ of the adolescents 
used water to clean their genital area, with the remaining majority using a cloth, salty water, soap, or disinfectant.

However, due to the COVID 19 protocols, $95.5 \%$ of the schools had readily available water for handwashing. Hand washing is important for menstrual hygiene practice and also of equal importance is having water for a shower or for washing their reusable menstrual clothes. Indicating that the presence of water and sanitation facilities as highlighted above helps to improve menstrual hygiene practice, reduces urinary tract infections/diseases, and also improves their reproductive health.

\section{CONCLUSIONS}

1) School-going adolescent girls (80\%) in Kibera have general knowledge on menstruation being a normal process for every girl to transition into womanhood.

2) Most teachers (61.5\%) are not trained in issues of menstruation and reproductive health.

3) There is little or no provision for menstrual hygiene, as only 3 out of the 22 schools had a washing/laundry area.

4) Due to the COVID 19 protocols, 21 of the 22 schools ensured that there was an area for washing of hands equipped with soap and water, with a few having water present for use in the toilets.

5) The pubescent girls had fair menstrual hygiene practices, as $98.8 \%$ of the adolescents use some form of menstrual absorbent material, $86 \%$ use a sanitary pad during menstruation, and $83.94 \%$ of the adolescents changed their menstrual material from 3 to 8 times a day. This was among several menstrual hygiene practices of adolescent girls that were documented above.

\section{Recommendations}

Based on the findings of the research, the following are the recommendations;

Improved support of sanitary materials and panties for adolescent girls from the government, NGOs, CBOs and other sponsors.

Conduct training for teachers on reproductive health by stakeholders (Ministry of Health and Ministry of Education).

Introduce a specific study guide on menstruation to be taught and distributed to the school going adolescent girls through the Ministry of Education.

Implement and follow-up of the existing Menstrual Hygiene Management Policy (2019-2030) in schools by stakeholders (Ministry of Education, Ministry of Health).

\section{Further research}

Further research is recommended in the following areas;

Impact of COVID 19 on the management of menstrual hygiene in adolescents.

Management of menstrual hygiene of school-going adolescent girls while at home.

\section{Acknowledgement}

I appreciate all the research respondents (senior teachers and Administrators) who willingly participated in the interviews and gave the approval to distribute the consent forms for guardians that made it possible to interview the girls in this research study. I also acknowledge the officials of the Ministry of Education, Mr. Simiyu from Nairobi County and Kibera Sub County for granting permission to undertake the study. I appreciate the support of Ms. Nondi, and Ms. Kilonzo from $\mathrm{MOH}$ who took me to all the 22 schools in Kibera Sub County.

Conflict of Interest: The authors declare no conflict of interest.

\section{Source of Funding: None}

\section{Ethical Approval: Approved}

\section{Data Availability}

Upon request, raw data are available from the corresponding author upon reasonable request. 
Joy N. Mokaya et.al. Management of menstrual hygiene among school-going adolescent girls in an informal settlement in Nairobi, Kenya, amidst COVID-19 pandemic.

\section{REFERENCES}

1. Sommer M, Sahin M. Overcoming the Taboo: Advancing the Global Agenda for Menstrual Hygiene Management for Schoolgirls. Am J Public Health [Internet]. 2013 Jul 18;103(9):1556-9. Available from: https://doi.org/10.2105/AJPH.2013.301374

2. Upashe SP, Tekelab T, Mekonnen J. Assessment of knowledge and practice of menstrual hygiene among high school girls in Western Ethiopia. BMC Womens Health [Internet]. 2015;15(1):84. Available from: https://doi.org/10.1186/s12905-015-0245-7

3. House S, Mahon T, Cavill S. Menstrual hygiene matters: a resource for improving menstrual hygiene around the world. Reprod Health Matters. 2013;21(41):257-9.

4. Seenivasan $P$, Priya K, Rajeswari C, Akshaya C, Sabharritha G, Sowmya K, et al. Knowledge, attitude and practices related to menstruation among adolescent girls in Chennai. J Clin Sci Res [Internet]. 2016 Jul 1;5(3):164-70. Available from: https://www.jcsr.co.in/article.asp?issn=2277 $-5706$

5. Sommer M, Caruso BA, Sahin M, Calderon T, Cavill S, Mahon T, et al. A Time for Global Action: Addressing Girls' Menstrual Hygiene Management Needs in Schools. PLOS Med [Internet]. 2016 Feb 23; 13(2):e1001962. Available from: https://doi.org/10.1371/journal.pmed.10019 62

6. Unterhalter E. Gender, schooling and global social justice. Routledge; 2012.

7. Millington KA, Bolton L. Improving access to menstrual hygiene products. Birmingham, UK Gov Soc Dev Resour Cent. 2015;

8. Sommer M, Sutherland C, Chandra-Mouli $\mathrm{V}$. Putting menarche and girls into the global population health agenda. Reprod Health [Internet]. 2015;12(1):24. Available from: https://doi.org/10.1186/s12978-0150009-8

9. Chebii S. Menstruation and education: how a lack of sanitary towels reduces school attendance in Kenyan slums. BUWA, Oct. 2014;27-31.

10. Raina D, Balodi G. Menstrual hygiene: knowledge, practise and restrictions amongst girls of Dehradun, Uttarakhand, India. Glob J Interdiscip Soc Sci. 2014;3(4):156-62.

11. Handa S, Peterman A, Huang C, Halpern C, Pettifor A, Thirumurthy H. Impact of the
Kenya Cash Transfer for Orphans and Vulnerable Children on early pregnancy and marriage of adolescent girls. Soc Sci Med. 2015;141:36-45.

12. Onyango P, Tostensen A. The Situation of youth and children in Kibera. C Rep. 2015;2015(3).

13. Benoit C, Roth E, Hallgrimsdottir $H$, Jansson M, Ngugi E, Sharpe K. Benefits and constraints of intimate partnerships for HIV positive sex workers in Kibera, Kenya. Int $\mathbf{J}$ Equity Health. 2013;12(1):1-12.

14. Gallaher CM, Kerr JM, Njenga M, Karanja NK, WinklerPrins AMGA. Urban agriculture, social capital, and food security in the Kibera slums of Nairobi, Kenya. Agric Human Values. 2013;30(3):389-404.

15. Aketch CO, Ngure K, Kiplangat JM. The effects of water quality and sanitation on immunocompromised: A case study of people living with HIV/AIDS in Kibera slum, Kenya. East Afr Med J. 2016;93(2):72-81.

16. Charan J, Biswas T. How to calculate sample size for different study designs in medical research? Indian J Psychol Med. 2013;35(2):121.

17. McCammon E, Bansal S, Hebert LE, Yan S, Menendez A, Gilliam M. Exploring young women's menstruation-related challenges in Uttar Pradesh, India, using the socioecological framework. Sex Reprod Heal matters. 2020;28(1):1749342.

18. Bhusal CK. Practice of menstrual hygiene and associated factors among adolescent school girls in Dang district, Nepal. Adv Prev Med. 2020;2020.

19. Amaya L, Marcatili J, Bhavaraju N. Advancing gender equity by improving menstrual health. Bost FSG. 2002;

20. Korir E, Okwara FN, Okumbe G. Menstrual hygiene management practices among primary school girls from a pastoralist community in Kenya: a cross sectional survey. Pan Afr Med J. 2018;31(1).

21. Kambala C, Chinangwa A, Chipeta E, Torondel B, Morse T. Acceptability of menstrual products interventions for menstrual hygiene management among women and girls in Malawi. Reprod Health. 2020;17(1):1-12.

22. Juyal R, Kandpal SD, Semwal J, Negi KS. Practices of menstrual hygiene among adolescent girls in a district of Uttarakhand. 
Joy N. Mokaya et.al. Management of menstrual hygiene among school-going adolescent girls in an informal settlement in Nairobi, Kenya, amidst COVID-19 pandemic.

Indian J community Heal. 2012;24(2):1248.

23. Sapkota D, Sharma D, Pokharel HP, Budhathoki SS, Khanal VK. Knowledge and practices regarding menstruation among school going adolescents of rural Nepal. J Kathmandu Med Coll. 2013;2(3):122-8.

24. Janoowalla H, Keppler H, Asanti D, Xie X, Negassa A, Benfield N, et al. The impact of menstrual hygiene management on adolescent health: The effect of Go! pads on rate of urinary tract infection in adolescent females in Kibogora, Rwanda. Int J Gynecol Obstet. 2020;148(1):87-95.

25. Chinyama J, Chipungu J, Rudd C, Mwale M, Verstraete L, Sikamo C, et al. Menstrual hygiene management in rural schools of Zambia: a descriptive study of knowledge, experiences and challenges faced by schoolgirls. BMC Public Health. 2019; 19(1):1-10.

26. Chisty MA, Afrose N, Shahrujjaman SM. Urban women's access to water and hygiene kits during menstruation in Dhaka city, International Journal of Natural and Social Sciences, 2020, 7(3):20-28.

27. Baku EA, Adrakpanya V, Konlan KD, Adatara P. Menstrual hygiene management among girls at a peri-urban senior high school in the Volta Region, Ghana. Afr J Midwifery Womens Health. 2020;14(1):112.
28. Jalan A, Baweja H, Bhandari M, Kahmei S, Grover A. A Sociological Study of the Stigma and Silences around Menstruation. Journal of Thematic Analysis.;1(1):47-64.

29. Baku EAk, Agbemafle I, Kotoh AM, Adanu RMK. Parents' experiences and sexual topics discussed with adolescents in the Accra Metropolis, Ghana: a qualitative study. Adv Public Heal. 2018;2018.

30. Belayneh Z, Mekuriaw B. Knowledge and menstrual hygiene practice among adolescent school girls in southern Ethiopia: a cross-sectional study. BMC Public Health. 2019;19(1):1-8.

31. Boosey R, Prestwich G, Deave T. Menstrual hygiene management amongst schoolgirls in the Rukungiri district of Uganda and the impact on their education: a cross-sectional study. Pan Afr Med J. 2014;19.

32. Nyamayedenga VK, Tsvere M. Real Time Data Capture: A Response to Unsustainable Dumping of Disposable Diapers and Sanitary Pads in Gweru City, Zimbabwe. East African J Educ Soc Sci. 1(2):54-64.

How to cite this article: Joy N. Mokaya, Mary Muiruri, Francisca Ongecha. Management of menstrual hygiene among school-going adolescent girls in an informal settlement in Nairobi, Kenya, amidst COVID-19 pandemic. Int J Health Sci Res. 2022; 12(2): 246-259. DOI: https://doi.org/10.52403/ijhsr.20220235 